TITLE:

\title{
Final-Stage Site-Selective Acylation for the Total Syntheses of MultifidosidesA-C.
}

$\operatorname{AUTHOR}(\mathrm{S})$ :

Ueda, Yoshihiro; Furuta, Takumi; Kawabata, Takeo

\section{CITATION:}

Ueda, Yoshihiro ...[et al]. Final-Stage Site-Selective Acylation for the Total Syntheses of MultifidosidesA-C.. Angewandte Chemie: International Edition 2015, 54(41): 11966-11970

ISSUE DATE:

2015-10-05

URL:

http://hdl.handle.net/2433/202609

\section{RIGHT:}

This is the peer reviewed version of the following article: Ueda, Y., Furuta, T. and Kawabata, T. (2015), Final-Stage SiteSelective Acylation for the Total Syntheses of MultifidosidesA-C. Angew. Chem. Int. Ed., 54: 11966-11970, which has been published in final form at http://dx.doi.org/10.1002/anie.201504729. This article may be used for non-commercial purposes in accordance with Wiley Terms and Conditions for Self-Archiving.; The full-text file will be made open to the public on 28 AUG 2016 in accordance with publisher's 'Terms and Conditions for Self-Archiving'.; This is not the

published version. Please cite only the published version.; この論文は出版社版でありません。引用の際には出版社版 をご確認じ利用ください。 


\title{
Final-Stage Site-Selective Acylation for the Total Syntheses of Multifidosides A-C by Organocatalysis
}

\author{
Yoshihiro Ueda, Takumi Furuta, and Takeo Kawabata*
}

\begin{abstract}
The first total syntheses of multifidosides A-C have been achieved. The synthetic strategy is characterized by catalytic siteselective acylation of protecting-group-free precursors 5a-c (also natural glycosides) at the final stage. High functional-group-tolerance of the site-selective acylation promoted by organocatalyst 4 enabled conventionally difficult molecular transformation in a predictable and reliable manner. An advantage of this strategy is to avoid the risks of undesired side reactions during the removal of the protecting groups at the final stage of the total synthesis, which we actually encountered in our attempted total synthesis and also have been reported in the literature.
\end{abstract}

Predictability is one of the most important factors for designing the strategy of target-oriented synthesis ${ }^{[1]}$ because rational retrosynthesis relies on the chemical transformations with predictable selectivity. Retrosynthetic analyses have been proposed based on the expected chemo-, diastereo-, and/or enantioselectivity of the corresponding reactions. In addition to these selectivities, site-selectivity has been a current focus as a key factor to streamline the synthetic routes to complex molecules $^{[2-4]}$. Recently, we reported total synthesis of natural glycosides of an ellgitannin family based on site-selective introduction of galloyl groups to unprotected glucose at an early stage of the total synthesis ${ }^{[5]}$. Here we report the first total syntheses of natural glycosides, multifidosides A, B, and C, via final-stage site-selective acylation (Figure 1). In the most cases of total syntheses, the final step is employed for deprotection of the protective groups. It has been believed that the key reaction should not be run at the final step because synthetic efforts may be hampered by the final step if the key reaction did not take place in the expected manner. On the other hand, the present site-selective acylation was found to be suitable to be performed at the final stage of the total synthesis, because the siteselectivity was maintained throughout the acylation of various natural glycosides precursors without exception, and thus, this site-selective molecular transformation seems predictable and reliable ${ }^{[6]}$. Recently, late-stage site-selective functionalization of biologically active compounds has been receiving increasing attention because it enables diversification of biologically active compounds retaining their original activity ${ }^{[7]}$. Final-stage siteselective functionalization is expected to be a more promising entry to conveniently providing natural products and their derivatives with the related biological activity.

Synthetic targets 1-3 (Figure 1) were isolated in 2008 by Zhao

[*] Dr. Y. Ueda, Dr. T. Furuta, Prof. Dr. T. Kawabata Institute for Chemical Research, Kyoto University Gokasho, Uji city, Kyoto 611-0011 (Japan)

E-mail: Kawabata@scl.kyoto-u.ac.jp

[**] This work was financially supported by Grant-in-Aids for Scientific Research on Innovative Areas "Advanced Molecular Transformations by Organocatalysts" and for Scientific Research (S) from MEXT. We are grateful to Prof. W.-M. Zhao at the Chinese Academy of Sciences for providing NMR spectra of natural multifidosides A-C.

Supporting Information for this article is given via a link at the end of the document. and co-workers from whole plants of Pteris multifida used for a traditional Chinese medicine ${ }^{[8]}$. Compounds $\mathbf{1}$ and $\mathbf{2}$ were reported to have significant cytotoxicity against HepG2 tumor cells. These glycosides possess a $p$-coumaroyl group at $\mathrm{C}(4)$ $\mathrm{OH}$ of the glucopyranose moiety. A retrosynthetic analysis of $\mathbf{1}$ and 2 is shown in Figure 1. While properly protected precursor 6 with the free $\mathrm{C}(4)-\mathrm{OH}$ (route 2) is a rational precursor for the synthesis of $\mathbf{1}$ and $\mathbf{2}$ based on the conventional protection/deprotection strategy, we envisioned to introduce the p-coumaroyl group directly onto the $\mathrm{C}(4)-\mathrm{OH}$ of the protectinggroup-free precursor $\mathbf{5}$ by site-selective acylation with organocatalyst 4 (route 1 ). In light of high functional-grouptolerance observed in the previously reported site-selective acylation reactions, ${ }^{[5,6]}$ we anticipated that the desired $4-O-$ acylation would take place through the hypothetical transition state (Figure 1 ) in the presence of otherwise more reactive primary hydroxy group(s) and other hydrogen-bond acceptors. The expected advantages of the present strategy would involve (1) a proposal of an unconventional retrosynthetic route to natural glucosides with $\mathrm{C}(4)$-O-acylated glucopyranose substructure, (2) shorter synthetic steps by streamlining the synthetic scheme, and (3) avoidance of the risks of the undesired side reactions during the removal of the protecting groups (PGs) at the later stage, which we actually encountered in our attempted total synthesis (see Scheme 3). The examples of undesired side reactions at the late-stage deprotection have also been reported toward to the synthesis of phenylethanoid glycosides, which include acyl migration, over reduction, and isomerization of the double bond ${ }^{[9]}$. Notably, the proposed synthetic scheme realizes an one-step conversion from a natural glycoside to other natural glycoside, since precursor $\mathbf{5}$ is also a naturally occurring glycoside, wallichoside ${ }^{[10]}$.

A retrosynthetic analysis for natural glycosides $\mathbf{5 a - c}(\mathbf{5 a}$ $(2 S, 3 S)$-wallichoside, $\mathbf{5 b}$ : $(2 R, 3 S)$-wallichoside, $\mathbf{5 c}$ : pteroside $\mathrm{B})$,

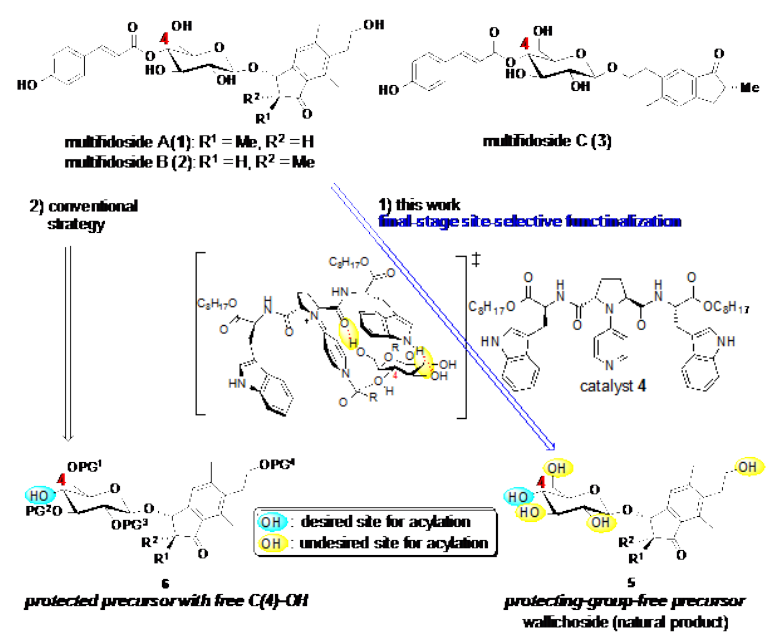

Figure 1. Structures of multifidosides A-C and synthetic strategy: route 1 (this work); organocatalytic final-stage site-selective acylation of the protectinggroup-free precursor, $\mathbf{5}$ and route 2 ; conventional strategy using a properly protected precursor, $\mathbf{6}$. 
the precursors of target natural glycosides 1-3, is shown in Scheme 1. Glycosides 5a-c would be obtained by $\beta$-selective glycosylation of aglycons $\mathbf{8 a}, \mathbf{8 b}$, and $\mathbf{1 0}$ with commercially available glycosyl donor $\mathbf{1 1}$ followed by debenzylation. Aglycons $\mathbf{8 a}, \mathbf{8 b}$, and $\mathbf{1 0}$ are also natural products known as $(2 S, 3 S)$ pterosin C, $(2 R, 3 S)$-pterosin C, and $(2 R)$-pterosin $\mathrm{B}^{[10]}$, respectively. The $\beta$-hydroxyketone moiety of $\mathbf{8} \mathbf{a}$ and $\mathbf{8} \mathbf{b}$ would be constructed by an organocatalytic intramolecular asymmetric aldol reaction of aromatic ketoaldehyde 12. Although the relative stereochemistry of the aldol reaction could not be predicted at this stage, both the syn- and anti- isomers were required because they both are constituents of the natural products, and the interconversion between them seemed possible by epimerization at $\mathrm{C}(2)$. Aglycon $\mathbf{1 0}$ would be readily obtained by reductive removal of the hydroxy group of $\mathbf{8} \mathbf{b}^{[11]}$.

Total synthesis of $\mathbf{2}$ was investigated at first (Scheme 2). The aldol precursor 12 was prepared from commercially available tetra-substituted benzene 13. Consecutive lithium-halogen exchange of $\mathbf{1 3}$ followed by hydroxyethylation and formylation of the respective aryl lithium species afforded a tri-substituted benzaldehyde derivative, which was then converted to 14 by reduction of the formyl group and methoxycarbonylation of the resulting alcohol. After iodination of $\mathbf{1 4}$ with $\mathrm{I}_{2}$ and PIFA ${ }^{[12]}$, intramolecular $O$ to $C$ acyl migration of the aryl magnesium species generated by iodine-magnesium exchange of the resulting aryl iodine followed by methanolysis gave lactone $\mathbf{1 5}$. Protection of the primary hydroxy group of $\mathbf{1 5}$ with a TBDPS group, addition of a Grignard reagent to the lactone, followed by Ley oxidation ${ }^{[13]}$ of the resulting lactol gave aldol precursor $\mathbf{1 2}$.

Then, the asymmetric intramolecular aldol reaction of ketoaldehyde 12 was investigated. Since List, Lerner, and Barbas reported the direct asymmetric aldol reaction between aliphatic ketones and aldehydes catalyzed by L-proline ${ }^{[14]}$, a tremendous number of organocatalytic asymmetric aldol reactions and related reactions have been reported ${ }^{[15]}$. However, there are only limited examples of direct aldol reactions using arylalkylketones as aldol donors because of the poor reactivity ${ }^{[16]}$. After thorough screening of catalysts and the conditions (Table S1), we found that proline derivative $16^{[17]}$ has reactivity sufficient to give $\mathbf{9 b}$ with the desired absolute and relative configuration (88\% yield, syn:anti=98:2, 85\% ee for the syn isomer). To the best of our knowledge, this is the first successful example of the asymmetric intramolecular aldol reaction of aromatic ketoaldehydes catalyzed by proline or its analogues. $\beta$-Selective glycosylation of $\mathbf{9 b}(85 \%$ ee) took place by treatment with commercially available glycosyl donor $11 \mathrm{a}$ and $\mathrm{BF}_{3} \cdot \mathrm{Et}_{2} \mathrm{O}$ in $\mathrm{EtCN}^{[18]}$ to give a diastereomeric mixture of the $\beta$-glycosides resulting from a $92.5: 7.5$ enantiomeric mixture of $\mathbf{9 b}$. Diastereomerically pure $\mathbf{1 7 b}$, obtained by the removal of the minor diastereomer, was subjected to the removal of TBDPS and Bn groups to afford $\mathbf{5 b}$, the proposed precursor for 2 .

Organocatalytic site-selective coumaroylation of $\mathbf{5 b}$ was next investigated toward the total synthesis of 2 . The use of lesscoordinating solvents such as $\mathrm{CHCl}_{3}$ or toluene was claimed to be critical for achieving high site-selectivity of the acylation of glycopyranoses catalyzed by $4^{[6]}$, which was assumed to be due to the effective hydrogen-bonding interaction in these solvents as shown in Figure 1. However, $\mathbf{5 b}$, the substrate for the $p$ -
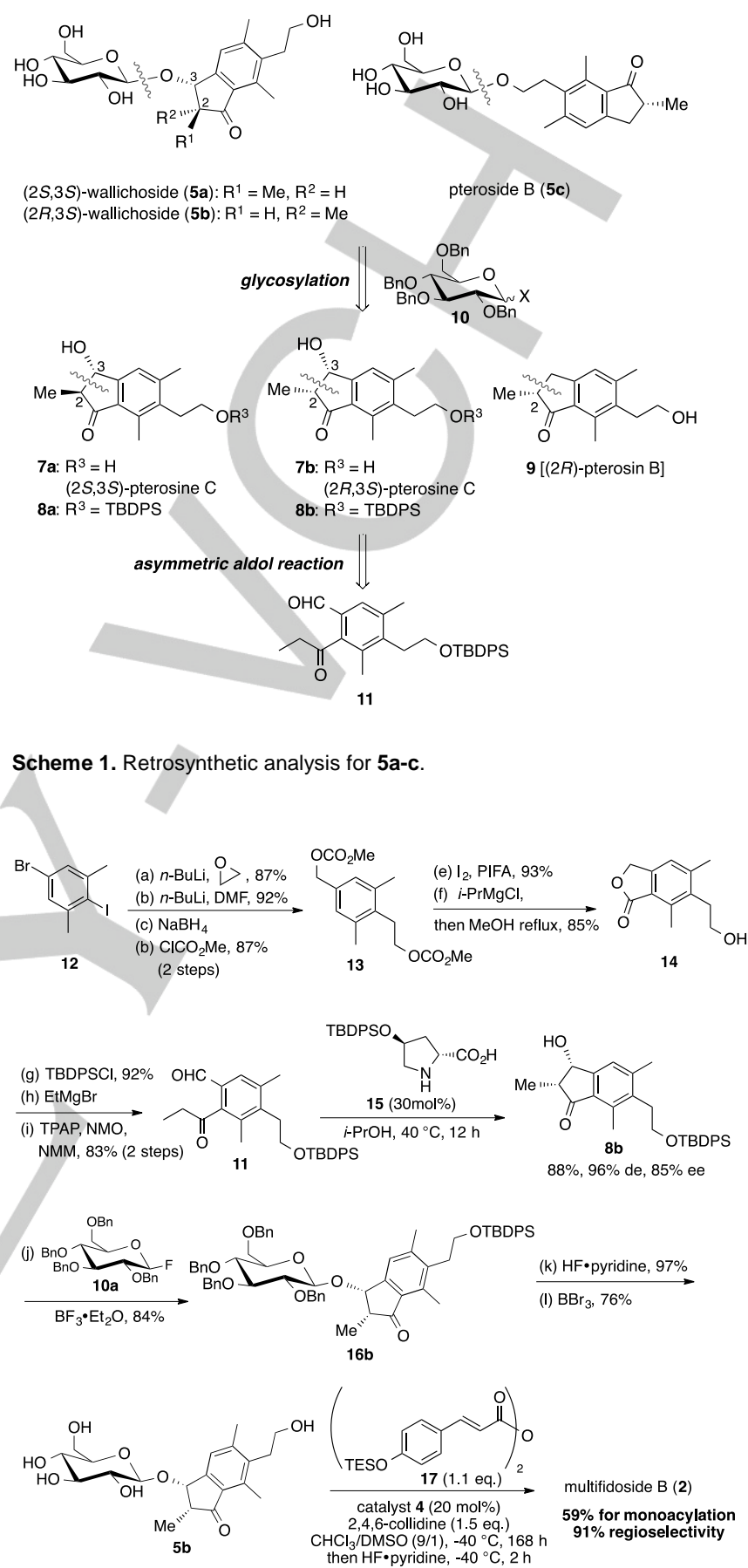

Scheme 2. Total synthesis of multifidoside B (2). Reagents and conditions: a) $n$-BuLi, $\mathrm{Et}_{2} \mathrm{O},-78^{\circ} \mathrm{C}$; ethylene oxide, $-78{ }^{\circ} \mathrm{C}$ to r.t., $87 \%$; b) $n$-BuLi, THF, -78 to $-30{ }^{\circ} \mathrm{C}$; DMF, $-78{ }^{\circ} \mathrm{C}$ to r.t., $92 \%$; c) $\mathrm{NaBH}_{4}, \mathrm{MeOH}, 0{ }^{\circ} \mathrm{C}$; d) methyl chloroformate, pyridine, DMAP (5 mol\%), DCM, r.t., 87\% (2 steps); e) I2, PIFA. $\mathrm{CH}_{3} \mathrm{CN}$, r.t., 93\%; f) $\mathrm{i}$-PrMgCl, THF, $0{ }^{\circ} \mathrm{C}$; $\mathrm{MeOH}$, reflux, 85\%; g) TBDPSCl, imidazole, r.t., 92\%; h) EtMgBr, THF, $0{ }^{\circ} \mathrm{C}$; i) TPAP (5 mol\%), NMO, NMM, MS $4 \AA$, DCM, r.t., $83 \%$ (2 steps); j) $11 \mathbf{a}(X=\beta-F), B_{3} \cdot \mathrm{Et}_{2} \mathrm{O}, \mathrm{MS} 4 \AA$, EtCN, -78 to $0{ }^{\circ} \mathrm{C}, 84 \%$; k) HF.pyridine, THF, r.t., $97 \%$ I) $\mathrm{BBr}_{3}, \mathrm{DCM},-78{ }^{\circ} \mathrm{C}, 76 \%$.

coumaroylation possessing five free hydroxy groups, was totally insoluble in $\mathrm{CHCl}_{3}$ or toluene. Instead of these solvents, $\mathrm{CHCl}_{3} / \mathrm{DMSO}(9 / 1)$ was found to be effective for the 
site-selective acylation at the $\mathrm{C}(4)-\mathrm{OH}$ of the glucopyranose derivative irrespective of the strongly hydrogen-bond accepting nature of DMSO ${ }^{[19]}$. TES-protected anhydride $\mathbf{1 8}$ was employed as an acylating reagent because the use of acid anhydrides rather than acid chlorides was critical for the site-selectivity[6a] and the TES group was expected to be readily removed at the work-up process. As expected, site-selective acylation of $\mathbf{5 b}$ catalyzed by 4 took place at the desired site to give natural glycoside 2 directly in 54\% isolated yield (91\% site-selectivity among the monoacylates obtained in $59 \%$ yield). This result showed that the site-selective acylation is highly functionalgroup tolerant in the presence of many potentially nucleophilic hydroxy groups, hydrogen-bond donors $(-\mathrm{OH})$ and acceptors (ketone, ethereal oxygen). The surprising functional-group tolerance of the site-selective acylation makes the present strategy reliable and predictable ${ }^{[20]}$.

This strategy provides additional advantages in the total synthesis by avoiding the risks of undesired side reactions (Scheme 3). For example, attempted total synthesis of $\mathbf{2}$ using partially protected precursor $\mathbf{1 8 b}$ resulted in the double-bond isomerization to give an $E / Z(2 / 1)$ mixture of 2 by the final-step deprotection of the OTBDPS group in $\mathbf{2 0}$ with TBAF/AcOH or $\mathrm{HF} /$ pyridine. Whereas the double bond in the hydroxy cinnamoyl group of the natural products has been reported to easily undergo $E, Z$-isomerization ${ }^{[9 c, 21]}$, only a small extent of $E, Z$ isomerization of 2 was observed $(E / Z=20 \sim 10 / 1)$ in our strategy shown in Scheme 2 (Natural products 1, 2, and $\mathbf{3}$ also contain a small amount of the $Z$-isomer, see Supporting information Figure S1-S3). Another attempt to obtain 2 by treatment of $\mathbf{2 0}$ with TBAF hampered the efforts to the total synthesis, and gave decomposed product $\mathbf{2 1}$ as the major product by $\beta$-elimination of the glucose moiety ${ }^{[22]}$. In the literature for the total synthesis of 4$O$-acylated glycoside natural products, undesired side reactions such as acyl migration from the desired 4-O-acylate to the undesired 6-O-acylate and over-reduction and isomerization of the cinnamoyl moiety by the final-step deprotection have been reported ${ }^{[9]}$. These problems could be avoided when the present strategy with protecting-group-free precursors is employed.

Total syntheses of $\mathbf{1}$ and $\mathbf{3}$ were performed by the similar procedure to that for the synthesis of 2 (Scheme 4). Epimerization at the carbonyl $a$-carbon of $17 b$ took place by the careful basic treatment at $0{ }^{\circ} \mathrm{C}$ to give a $86: 14$ mixture of $17 \mathrm{a}$ and $17 \mathrm{~b}$ without $\beta$-elimination of the glucose moiety (Scheme $4 \mathrm{~A}$ ). Separation of the resulting diastereomers gave $17 \mathbf{a}$ as a pure diastereomer in $70 \%$ yield. $(2 S, 3 S)$-Wallichoside (5a) was obtained by removal of the protective groups of $17 \mathbf{a}$. Organocatalytic site-selective coumaroylation of $\mathbf{5 a}$ with five free hydroxy groups took place also in a predictable manner to give a natural product, multifidoside A (1), in 54\% isolated yield (Scheme 4A, 84\% site-selectivity among the monoacylates obtained in $64 \%$ yield). Aglycon 10 , the proposed precursor of 3 , was prepared by Barton-McComby deoxygenation ${ }^{[23]}$ of $9 \mathbf{b}$ followed by desilylation (Scheme 4B). Glycosylation of 10 by Schmidt's procedure ${ }^{[18 b, 24]}$ followed by hydrogenation of the resulting glycoside gave pteroside $\mathrm{B}^{[10]}(5 \mathrm{c})$. Total synthesis of multifidoside C (3) was achieved by catalytic site-selective coumaroylation of $\mathbf{5 c}$ in $70 \%$ isolated yield $(90 \%$ site-selectivity among the monoacylates obtained in $78 \%$ yield). Thus, total syntheses of natural glycosides, multifidosides $A, B$, and C, were accomplished via final-stage organocatalytic site-selective coumaroylation of the precursors with multiple free hydroxyl groups.

The desired site-selectivity was maintained throughout the acylation of the glycosides with various aglycon moieties. Another advantage of this strategy is the direct and facile diversification of natural glycosides (Scheme 5). Isobutyryl, benzoyl, and $N$-Cbz- $\alpha$-aminoacyl groups were introduced to the expected hydroxy group of a natural glycoside, $(2 R, 3 S)$ wallichoside (5b), in up to $97 \%$ site-selectivity by the protocol described above. The biological activity of carbohydrates possessing acyl group(s) often depends on the position and structure of the acyl group(s) ${ }^{[25,26]}$. Therefore, the site-selective introduction of various acyl groups at the final stage of the synthesis may be applicable to searching for the biologically active analogues.

In conclusion, the first total syntheses of multifidosides A (1), $B$ (2) and C (3) have been accomplished in 15 steps $(8.2 \%$ overall yield), 14 steps ( $12 \%$ overall yield), and 16 steps $(11 \%$ overall yield), respectively, from commercially available reagents.

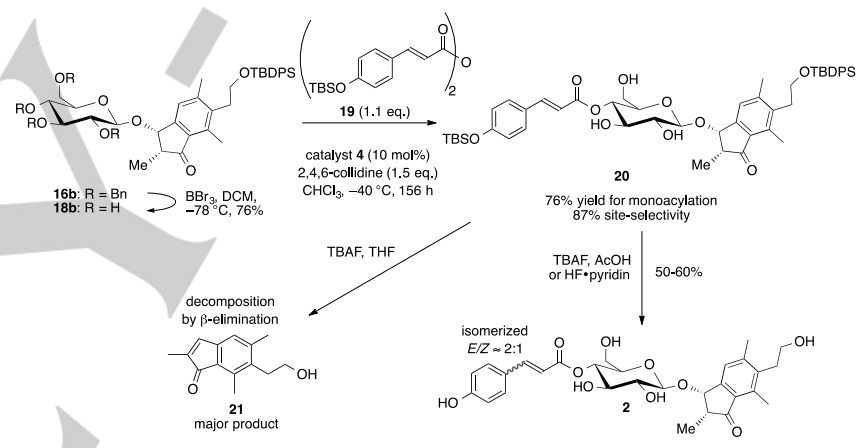

Scheme 3. Our problems encountered at the later-stage deprotection toward total synthesis of 2 .
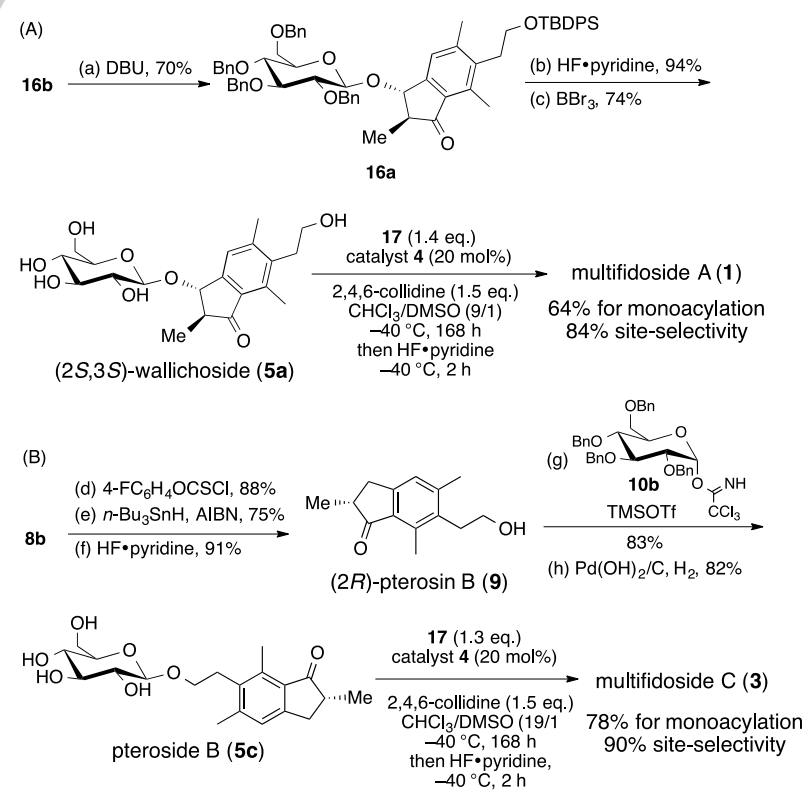
Scheme 4. Total syntheses of (A) 1 and (B) 3. Reagents and Conditions: a) $\mathrm{DBU}$, toluene, $0{ }^{\circ} \mathrm{C}, 70 \%$; b) HF.pyridine, THF, r.t., 94\%; c) $\mathrm{BBr} 3, \mathrm{DCM}$, $78{ }^{\circ} \mathrm{C}, 74 \%$; d) 22,4 (20 mol\%), collidine, $\mathrm{CHCl}_{3} / \mathrm{DMSO}(9 / 1),-40{ }^{\circ} \mathrm{C}, 168 \mathrm{~h}$; HF.pyridine, $-40{ }^{\circ} \mathrm{C}, 2 \mathrm{~h}$; e) $4-\mathrm{FC}_{6} \mathrm{H}_{4} \mathrm{OCSCl}$, DMAP, DCM, r.t., 88\%; f) $n$ $\mathrm{Bu}_{3} \mathrm{SnH}$, AIBN (20 mol\%), benzene, $100{ }^{\circ} \mathrm{C}, 75 \%$; g) HF.pyridine, THF, r.t. $91 \%$; h) 11b, TMSOTf (10 mol\%), $\mathrm{CH}_{3} \mathrm{CN},-40{ }^{\circ} \mathrm{C}, 83 \%$, (s) $\mathrm{Pd}(\mathrm{OH})_{2} / \mathrm{C}, \mathrm{H}_{2}$, AcOEt/MeOH (1/1), r.t., $82 \%$.

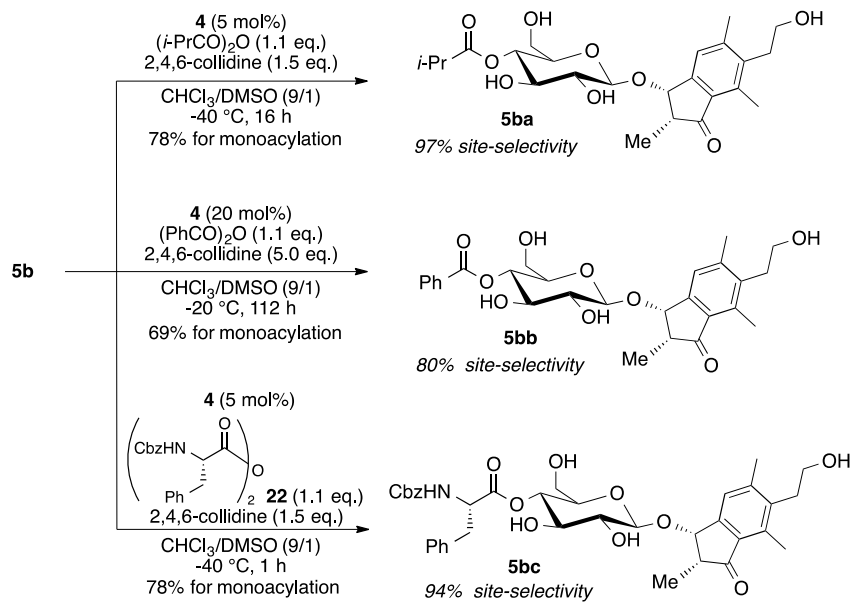

Scheme 5. Final-stage site-selective diversification of a natural product, $(2 R, 3 S)$-wallichoside $\mathbf{( 5 b})$

The key step is the final-stage site-selective acylation of the protecting-group-free precursors by organocatalysis. Because of the predictability and reliability of the catalytic site-selective introduction of the various functionalized acyl groups, this synthetic strategy would provide a new retrosynthetic route to 4$O$-acylglycosides such as phenylethanoid glycosides ${ }^{[27]}$ and ellagitannins $^{[28]}$ of biological interest.

Keywords: acylation $\bullet$ natural glycoside $\bullet$ organocatalyst $\bullet$ siteselectivity• retrosynthesis

[1] a) M. S. Chen, M. C. White, Science 2007, 318, 783-787; b) D. Lapointe, T. Markiexicz, C. J. Whipp, A. Toderian, K. Fagnou, J. Org. Chem. 2011, 76, 749-759; c) P. E. Gormisky, M. C. White, J. Am. Chem. Soc. 2013, 135, 14052-14055.

[2] For the recent examples of site-selective functionalization to the direct diversification of bioactive natural products, see a) Robles, D. Romo, Nat. Prod. Rep. 2014, 31, 318-334; b) P. A. Lichtor, S. J. Miller, Nat. Chem. 2012, 4, 990-995; c) T. P. Pathak, S. J. Miller, J. Am. Chem. Soc. 2013, 135, 8415-8422; d) S. Han, S. J. Miller, J. Am. Chem. Soc. 2013, 135, 12414-12421.

[3] For an excellent example of site-selective $\mathrm{C}-\mathrm{H}$ oxidation toward a total synthesis of 6-deoxyerythronolide B, see E. M. Stang, M. C. White, Nat. Chem. 2009, 1, 547-551.

[4] For the representative recent examples of the site-selective functionalization of carbohydrates, see: a) D. Lee, M. S. Taylor Synthesis 2012, 44, 3421-3431; b) X. Sun, H. Lee, S. Lee, K. L. Tan Nat. Chem. 2013, 5, 790-795; c) D. Lee, C. L. Williamson, L. Chan, M. S. Taylor, J. Am. Chem. Soc. 2012, 134, 8260-8267; d) W. Muramatsu, S. Tanigawa, Y. Takemoto, H. Yoshimatsu, O. Onomura, Chem. Eur. J. 2012, 18, 4850-4853.

[5] H. Takeuchi, K. Mishiro, Y. Ueda, Y. Fujimori, T. Furuta, T. Kawabata, Angew. Chem. Int. Ed. 2015, 54, 6177-6189.
[6] a) T. Kawabata, W. Muramatsu, T. Nishio, T. Shibata, H. Schedel, J. Am. Chem. Soc. 2007, 129, 12890-12895; b) Y. Ueda, W. Muramatsu K. Mishiro, T. Furuta, T. Kawabata, J. Org. Chem. 2009, 74, 88028805 ; c) Y. Ueda, K. Mishiro, K. Yoshida, T. Furuta, T. Kawabata, J. Org. Chem. 2012, 77, 7850-7857.

[7] For example, see: D. A. DiRocco, K. Dykstra, S, Krska, P. Vachal, D. V. Conway, M. Tudge, Angew. Chem. Int. Ed. 2014, 53, 4802-4806.

[8] X. Ge, G. Ye, P. Li, W.-J. Tang, J.-L. Gao, W.-M. Zhao, J. Nat. Prod 2008, 71, 227-231.

[9] a) T. Kawada, R. Asano, K. Makino, T. Sakuno, J. Wood Sci. 2002, 48 512-515; b) T. Kawada, R. Asano, K. Makino, T. Sakuno, Eur. J. Org. Chem. 2000, 2723-2727; c) H. I. Duynstee, M. C. de Koning, H. Ovaa G. A. van der Marel, J. H. van Boom, Eur. J. Org. Chem. 1999, 2623 2632; d) S.-Q. Zhang, Z.-J. Li, A.-B. Wang, M.-S. Cai, R. Feng, Carbohydr. Res. 1997, 299, 281-285.

[10] a) M. Kuroyanagi, M. Fukuoka, K. Yoshihira, S. Natori, Chem. Pharm. Bull. 1979, 27, 592-601; b) M. Fukuoka, M. Kuroyanagi, K. Yoshihira, S Natori, Chem. Pharm. Bull. 1978, 26, 2365-2385; c) P. Sengupta, M. Sen, S. K. Niyogi, S. C. Pakrashi, E. Ali, Phytochemistry 1976, 15, 995998.

[11] Total syntheses of racemic pterosins B (racemic-10) and C (racemic8a) have been reported. a) P. Wessig, J. Teubner, Synlett 2006, 15431546; b) K.-M. E. Ng, T. C. McMorris, Can. J. Chem. 1984, 62, 19451953

[12] a) E. B. Merkushev, N. D. Simakhina, Synthesis 1980, 486-487; b) T Muraki, H. Togo, M. Yokoyama, J. Org. Chem. 1999, 64, 2883-2889.

[13] W. P. Griffith, S. V. Ley, G. P. Whitcombe, A. D. White, J. Chem. Soc., Chem. Commun. 1987, 1625-1627.

[14] B. List, R. A. Lerner, C. F. Barbas, J. Am. Chem. Soc. 2000, 122 2395-2396.

[15] a) P. H.-Y. Cheong, C. Y. Legault, J. M. Um, N. Çelebi-Ölçüm, K. N. Houk, Chem. Rev. 2011, 111, 5042-5137; b) S. Mukherjee, J. W. Yang, S. Hoffmann, B. List, Chem. Rev. 2007, 107, 5471-5569; c) S. Saito, H. Yamamoto, Acc. Chem. Res. 2004, 37, 570-579.

[16] a) H. Torii, M. Nakadai, K. Ishihara, S. Saito, H. Yamamoto, Angew. Chem. Int. Ed. 2004, 43, 1983-1986; b) K. Mei, S. Zhang, S. He, P. Li, M. Jin, F. Xue, G. Luo, H. Zhang, L. Song, W. Duan, W. Wang, Tetrahedron Lett. 2008, 49, 2681-2684; c) R. D. Carpenter, J. C. Fettinger, K. S. Lam, M. J. Kurth, Angew. Chem. Int. Ed. 2008, 47, 6407-6410; d) K. Funabiki, Y. Itoh, Y. Kubota, M. Matsui, J. Org. Chem. 2011, 76, 3545-3550.

[17] a) Y. Hayashi, T. Sumiya, J. Takahashi, H. Gotoh, T. Urushima, M Shoji, Angew. Chem. Int. Ed. 2006, 45, 958-961; b) N. Itagaki, M. Kimura, T. Sugahara, Y. Iwabuchi, Org. Lett. 2005, 7, 4185-4188.

[18] a) S. Hashimoto, M. Hayashi, R. Noyori, Tetrahedron Lett. 1984, 25, 1379-1382; b) X. Zhu, R. R. Schmidt, Angew. Chem. Int. Ed. 2009, 48, 1900-1934.

[19] For the effects of DMSO in $\mathrm{CHCl}_{3}$ on site-selectivity in the acylation of glucopyranosides catalyzed by $\mathbf{4}$, see the Supporting Information. The possible use of a $\mathrm{CHCl}_{3} / \mathrm{DMSO}$ system was reported in geometryselective acylation of alkene diols. See K. Yoshida, K. Mishiro, Y. Ueda, T. Shigeta, T. Furuta, T. Kawabata, Adv. Synth. Catal. 2012, 354, 3291-3298.

[20] This strategy may be applicable to the synthesis of C(4)-O-acylated mannopyranose derivatives, based on our previous findings: see reference $5 a$.

[21] J. Rothenburger, E. Haslinger, Eur. J. Org. Chem. 1994, 1113-1115.

[22] The use of other protecting groups such as TBS and PMB groups, which were expected to be removed under acidic conditions to prevent the $E / Z$ isomerization, was found incompatible with the stability of the glycosides.

[23] D. H. R. Barton, P. Blundell, J. Dorchak, D. O. Jang, J. C. Jaszberenyi, Tetrahedron 1991, 47, 8969-8984.

[24] R. R. Schmidt, J. Michel, Angew. Chem. Int. Ed. Engl. 1980, 19, 731732. 
[25] a) J. Guiard, A. Collmann, M. Gilleron, L. Mori, G. De Libero, J. Prandi, G. Puzo, Angew. Chem. Int. Ed. 2008, 47, 9734-9738; b) U. Aich, C. T Campbell, N. Elmouelhi, C. A. Weier, S.-G. Sampathkumar, S. S. Choi, K. J. Yarema, ACS Chem. Biol. 2008, 3, 230-240.

[26] M. Boultadakis-Arapinis, P. Lemoine, S. Turcaud, L. Micouin, T. Lecourt, J. Am. Chem. Soc. 2010, 132, 15477-15479.
[27] C. Jiménez, R. Riguera, Nat. Prod. Rep. 1994, 11, 591-606.

[28] a) S. Quideau, D. Deffieux, C. Douat-Casassus, L. Pouységu, Angew. Chem. Int. Ed. 2011, 50, 586-621; b) S. Quideau, K. S. Feldman Chem. Rev. 1996, 96, 475-504. 
Entry for the Table of Contents (Please choose one layout)

Layout 2:

\section{COMMUNICATION}

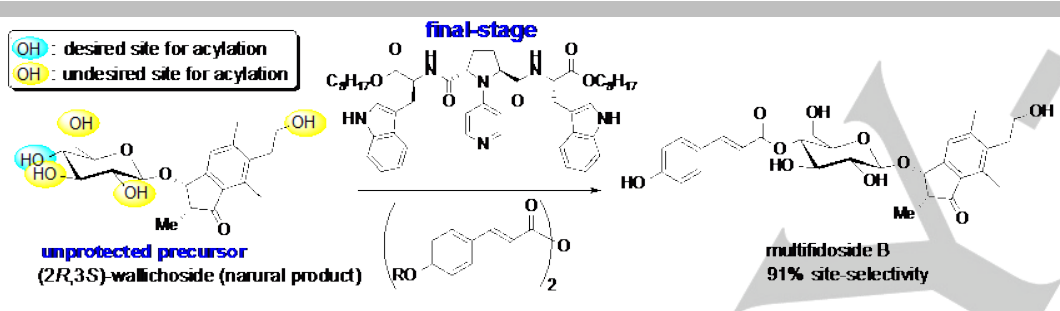

A new retrosynthetic route to 4-O-acylated natural and unnatural glycosides was proposed. Organocatalytic site-selective coumaroylation of the protective-groupfree precursors possessing multiple hydroxy groups was performed successfully at the final-stage of the total syntheses of multifidosides A, B, and C. The siteselectivity was found to be predictable and reliable throughout the acylation of the various protective-group-free precursors.
Yoshihiro Ueda, Takumi Furuta, Takeo Kawabata*

Page No. - Page No.

Final-Stage Site-Selective Acylation for the Total Syntheses of Multifidosides A-C by Organocatalysis 